\title{
Impact of the Inverter DC Bus Voltage on the Iron Losses of a Permanent Magnet Synchronous Motor at Constant Speed
}

\author{
Nicolas Denis ${ }^{* a)}$ Non-member, Yenyi $\mathrm{Wu}^{*}$ Non-member \\ Keisuke Fujisaki* Senior Member
}

(Manuscript received Dec. 26, 2016, revised May 24, 2017)

\begin{abstract}
In this paper, the impact of the DC bus voltage on the iron losses of a permanent magnet synchronous motor (PMSM) fed by a pulse-width modulation inverter is evaluated. Under constant speed operation, the modulation index decreases when the DC bus voltage increases. This modifies the harmonic content of the PMSM input voltage and then affects the motor iron losses. The experimental measurements results show that, for the conditions considered in this paper, the total iron losses are 1.8 times larger at the lowest modulation index than at the highest one.
\end{abstract}

Keywords: inverter, iron loss, magnetic material, permanent magnet synchronous motor

\section{Introduction}

Many researches demonstrate that the output voltage of a pulse-width modulation (PWM) inverter fed to any wound soft magnetic material tends to increase its iron losses compared to the case of sinusoidal voltage fed operation. Early literature assumes that the high frequency harmonic components in the PWM supplied voltage are responsible for extra eddy current losses only, implying that the hysteresis losses are only slightly impacted ${ }^{(1)}$. More thorough investigations show that high frequency magnetic flux density occurs inside the magnetic material, which is responsible for a skin effect that has a strong impact on the material iron losses ${ }^{(2)}$. Moreover, some researchers point out that those high frequency magnetic flux density variations can also cause minor hysteresis loops which increase the hysteresis losses in a sometimes non-negligible way ${ }^{(3)}$.

PWM gate signal generation has several parameters which can influence the iron losses in their own way. The impact of the modulation index in particular, has been studied on wound laminated ring cores ${ }^{(4)}$. The authors conclude that the material specific iron losses tend to increase when the modulation index decreases. One of the cause of this increase is that reducing the modulation index has for effect to widen the minor hysteresis loops in the material ${ }^{(5)}$.

Under the assumption that the harmonic content of the PWM supplied voltage is only responsible for extra eddy current losses, some authors are able to propose analytical formulas of the iron losses caused by PWM in transformers ${ }^{(6)}$. As a result, they propose an analytical characterization of the impact of the PWM modulation index on the iron losses.

As for the permanent magnet synchronous motors (PMSM), numerical analysis allows evaluating the iron losses

a) Correspondence to: Nicolas Denis. E-mail: nicolas.denis@ challenergy.com

* Toyota Technological Institute

2-12-1, Hisakata, Tenpaku-ku, Nagoya, Aichi 468-8511, Japan caused solely by $\mathrm{PWM}^{(7)}$. The physical repartition of these losses in the motor parts (rotor, stator and magnets) can also be evaluated by numerical analysis ${ }^{(8)}$. In particular, authors conclude that the magnet losses are almost only due to the eddy current caused by the PWM and that the effect of stator slots on the magnet losses is comparatively small. The additional iron losses caused by PWM can also be approximated using analytical formulas ${ }^{(9)(10)}$. In (9), the study focuses on a synchronous motor with surface-mounted permanent magnets (SPMSM). Both experiment and numerical calculation show that the motor iron losses decrease when the modulation index increases. However, the derivative is not considered in the motor equation used for the analytical model, even though the derivative has a significant impact on the current high order harmonics. In (10), the increasing rate of eddy current losses due to PWM is evaluated on a synchronous motor with interior permanent magnets (IPMSM). The motor uses ferrite magnets with high resistivity, which allows neglecting the magnet eddy current losses. Both the analytical calculation and the experiment show lower eddy current losses increasing rate at high modulation index. However, the high frequency content of the motor current due to the PWM carrier signal is considered using an rms value that depends on the PWM control parameters. Then the analytical model does not consider each harmonic of the voltage and current.

In this paper, an experimental methodology to evaluate the influence of the PWM modulation index on a synchronous motor with interior sintered $\mathrm{NdFeB}$ magnets is proposed. An analytical model is then developed to give the motor voltage and current harmonics as a function of the PWM control parameters, and especially the modulation index. In section 2 , the motor geometry and the cores material characteristics are presented. The section 3 explains the experimental methodology and provides the IPMSM total iron losses measurement results. The experiments are conducted at constant speed and the DC bus voltage is changed so that a fairly wide range of modulation index is covered. The section 4 develops an 


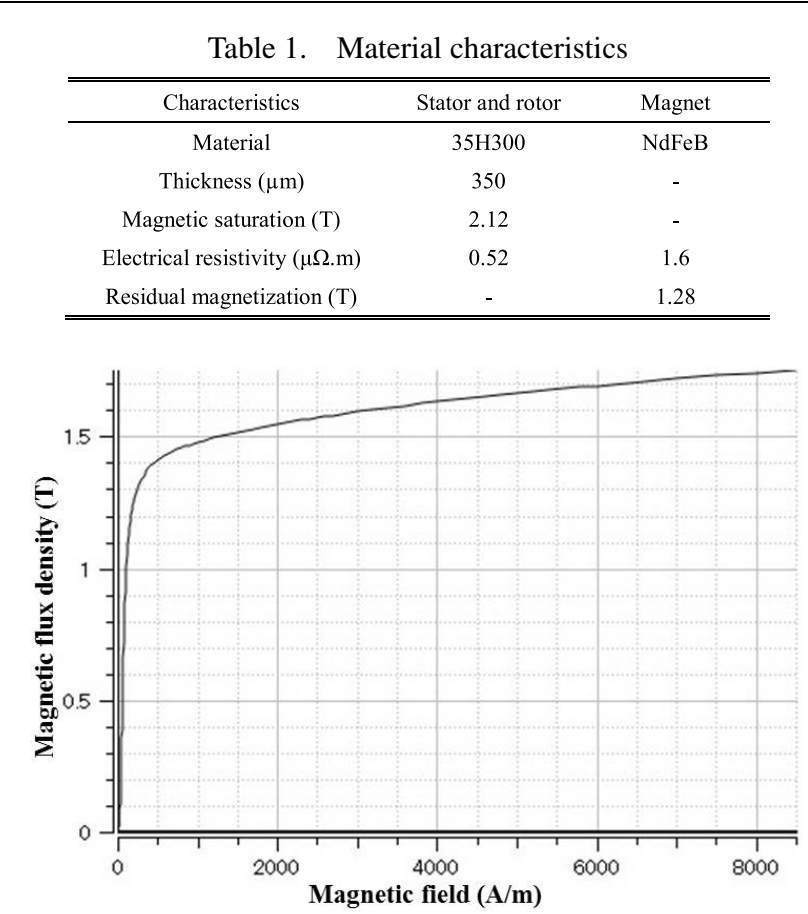

Fig. 1. $B-H$ characteristic of the $35 \mathrm{H} 300$ material

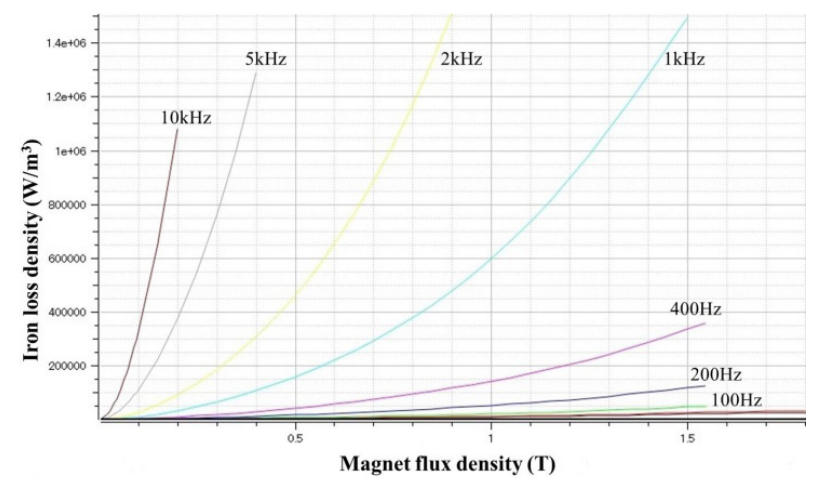

Fig. 2. Specific iron loss density of the $35 \mathrm{H} 300$ material

analytical model of the IPMSM voltage and current harmonics as functions of the PWM control parameters. Finally, measurements of the magnetic flux density in the stator are shown in section 5 .

\section{Material Characteristics and Motor Geometry}

2.1 Material Characteristics The stator and rotor of the proposed IPMSM are made of non-oriented electrical steel sheets $35 \mathrm{H} 300$. The permanent magnets are sintered $\mathrm{NdFeB}$. The important characteristics of the materials are shown in Table 1 . The $B-H$ and specific iron loss characteristics of the soft-magnetic material are given in Fig. 1 and Fig. 2 respectively.

2.2 Motor Geometry The cross-section view of the motor is illustrated in Fig. 3. The geometry characteristics and the motor electrical characteristics are listed in Table 2 and Table 3 respectively.

\section{Experimental Methodology and Measurement Results}

3.1 Experimental Methodology The experimental test bench is illustrated in Fig. 4. The IPMSM is driven by

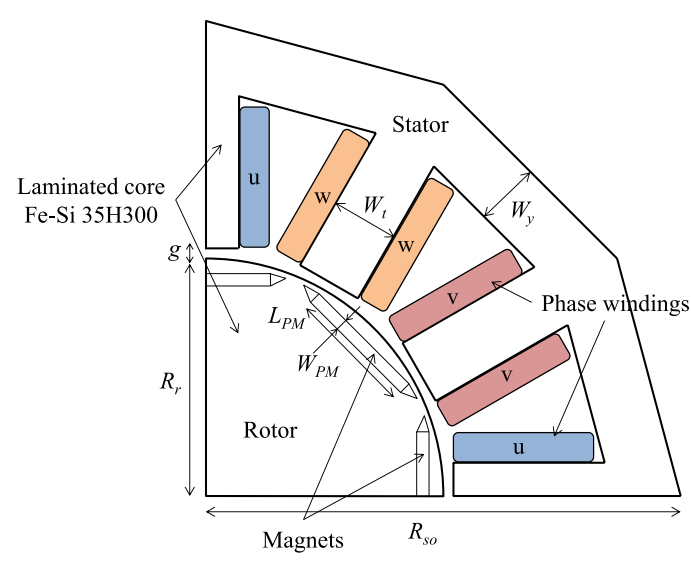

Fig. 3. Quarter cross-section view of the IPMSM

Table 2. IPMSM geometry characteristics

\begin{tabular}{cc}
\hline \hline Poles / Slot number & $8 / 12$ \\
Radius of stator core $R_{s o}$ & $64 \mathrm{~mm}$ \\
Radius of rotor core $R_{r}$ & $37 \mathrm{~mm}$ \\
Air gap $g$ & $1.25 \mathrm{~mm}$ \\
Yoke width $W_{y}$ & $9.2 \mathrm{~mm}$ \\
Tooth width $W_{t}$ & $10 \mathrm{~mm}$ \\
PM length $L_{P M}$ & $20 \mathrm{~mm}$ \\
PM thickness $W_{P M}$ & $2 \mathrm{~mm}$ \\
Core length $L_{c}$ & $47 \mathrm{~mm}$ \\
Number of winding turns & 37 \\
\hline \hline
\end{tabular}

Table 3. IPMSM electrical characteristics

\begin{tabular}{cc}
\hline \hline Phase resistance $R_{s}$ & $0.498 \Omega$ \\
d-axis inductance $L_{d}$ & $2.44 \mathrm{mH}$ \\
q-axis inductance $L_{q}$ & $3.70 \mathrm{mH}$ \\
Peak line to neutral back EMF at $750 \mathrm{rpm}$ & $20.1 \mathrm{~V}$ \\
\hline \hline
\end{tabular}

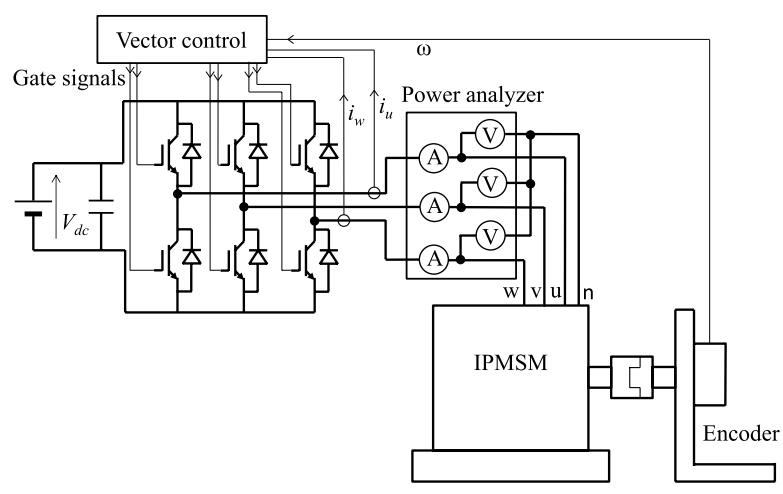

Fig. 4. Experimental test bench for the iron loss measurement

a three-phase two-level voltage source inverter (VSI) with IGBTs. The inverter input voltage $V_{d c}$ is provided by a DC power source. A standard vector control using a fixed frequency PWM with a triangular wave carrier signal is implemented for the speed control. The d-axis current reference is set to zero in the vector control scheme. No load is connected to the IPMSM rotor shaft but an encoder is still needed for the feedback of the shaft rotational speed.

The IPMSM input active electrical power $P_{3 \Phi}$ is measured using a power analyzer with a sampling frequency of $2.2 \mathrm{MHz}$ and a bandwidth from DC to $2 \mathrm{MHz}$. On the 
measurement window, the power analyzer performs the calculation

$$
P_{3 \Phi}=\frac{1}{N} \sum_{k=0}^{N-1}\left(\begin{array}{c}
i_{u}(k) v_{u n}(k)+i_{v}(k) v_{v n}(k) \\
+i_{w}(k) v_{w n}(k)
\end{array}\right) \ldots \ldots \ldots \ldots
$$

where $N$ is the sample number of the measurement window, $i_{u, v, w}$ are respectively the $u, v$ and $w$ phase currents, and $v_{u, v, w n}$ are respectively the $u, v$ and $w$ phase to neutral voltages. In order to calculate the copper losses, the rms current is obtained from the current waveform using the equation

$$
I_{x r m s}=\sqrt{\frac{1}{N} \sum_{k=0}^{N-1} i_{x}^{2}(k) \cdots \ldots \ldots \ldots \ldots \ldots \ldots \ldots \ldots \ldots}
$$

where $x$ can be $u, v$ or $w$ depending in the considered phase.

The inverter-fed IPMSM iron losses under no-load condition can then be calculated using the following equation

$$
P_{i \_n o l}=P_{3 \Phi}-R_{s}\left(I_{u r m s}^{2}+I_{v r m s}^{2}+I_{w r m s}^{2}\right)-P_{f} \cdots \cdots
$$

where $P_{f}$ are the mechanical losses of the IPMSM and the encoder that are measured beforehand using a rotor with demagnetized magnets. With this equation, it is assumed that the measured iron losses are the sum of the hysteresis losses and the eddy current losses in the stator core, rotor core and magnets.

In order to get an approximation of the impact of the PWM on the total iron losses by experiment, a test at no-current is done. The methodology of this test is explained in details in (11). During this test, an auxiliary brushless DC motor is used to rotate the IPMSM externally. The three phases of the IPMSM stator are in open circuit. Therefore, no current is flowing through the stator windings and the iron losses are caused by the rotating magnets only. In this condition, the IPMSM total iron losses is equal to $P_{i \_n o c}$ and the contribution of the PWM to the total iron losses is estimated using the simple equation

$$
P_{i_{-} P W M}=P_{i_{-n o l}}-P_{i_{-} n o c} \ldots \ldots \ldots \ldots \ldots \ldots \ldots \ldots
$$

3.2 Iron Loss Measurement Results The PWM carrier frequency is $1 \mathrm{kHz}$ and the inverter dead-time $3500 \mathrm{~ns}$. In order to evaluate the influence of the PWM modulation index on the iron losses, the measurements are made at a constant speed of $750 \mathrm{rpm}(50 \mathrm{~Hz})$ with different values of $V_{d c}$. When changing $V_{d c}$, the speed control loop modifies the value of the modulation index in order to adjust the inverter output voltage so that the speed is maintained constant. The values of $V_{d c}$ range from $180 \mathrm{~V}$ to $43 \mathrm{~V}$, which corresponds to a variation of modulation index $m_{a}$ from 0.230 to 0.975 .

The Fig. 5 shows the evolution of the DC bus voltage, the IPMSM total iron losses under no-current condition $P_{i \_n o c}$, no-load condition $P_{i_{-} n o l}$ and the IPMSM iron losses caused by the PWM $P_{i_{-} P W M}$. $P_{i_{-} \text {noc }}$ does not depend on the modulation index because the IPMSM is not driven by the inverter in no-current condition. At a modulation index $m_{a}$ of 0.230 , the PWM carrier frequency is responsible for as much as $66 \%$ of the total iron losses. At a modulation index of 0.975 , this ratio becomes $37 \%$.

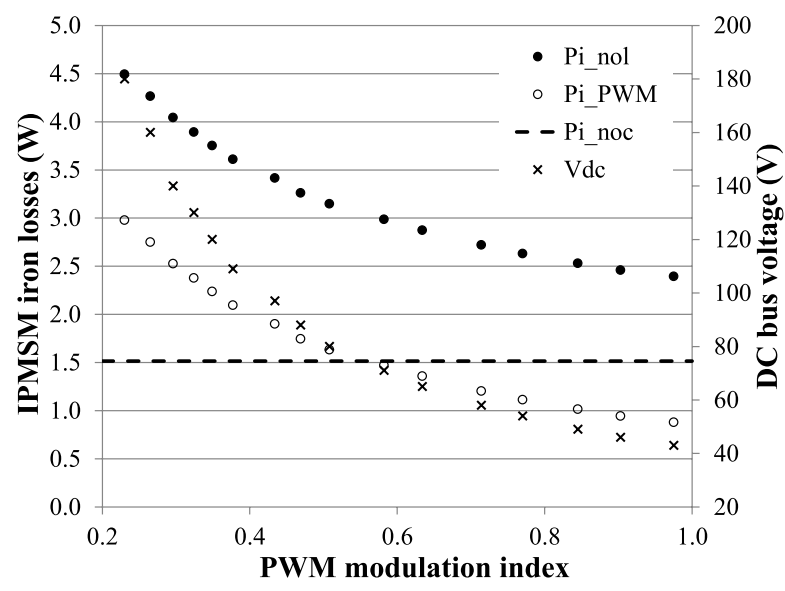

Fig. 5. IPMSM iron loss measurement
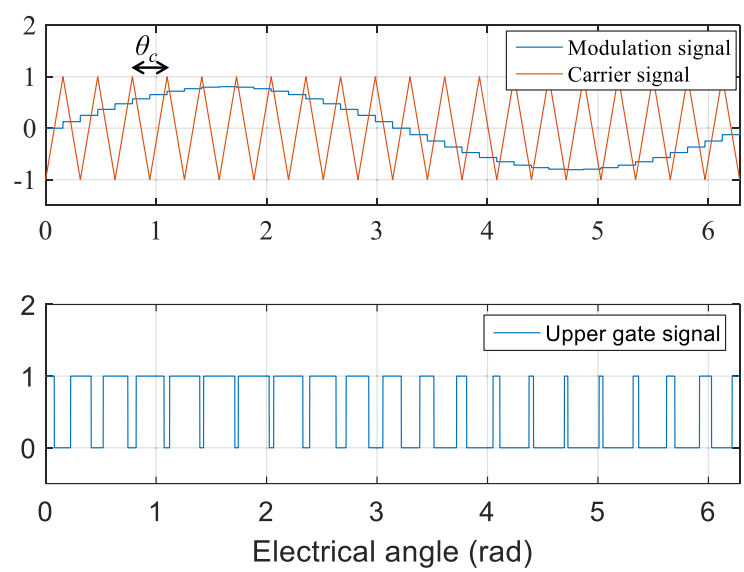

Fig. 6. PWM sampled modulation signal and triangular carrier signal (upper), and IGBT upper gate signal (bottom). Example for $u$ phase with $m_{a}=0.8, F_{c}=1 \mathrm{kHz}$ and $F_{e}=50 \mathrm{~Hz}$

\section{Analytical Model of Motor Voltage and Cur- rent}

4.1 Calculation of Motor Phase Voltage Harmonics As explained section 3, the PWM uses a triangular wave shape of frequency $F_{c}$ and a sinusoidal modulation signal whose amplitude is given by the modulation index $m_{a}$ and frequency is equal to the IPMSM electrical frequency $F_{e}$. The modulation signal is sampled at two times the carrier frequency, which gives the IGBT gate signal illustrated in Fig. 6. The switch OFF points $\theta_{k, o f f, u}$ and switch ON points $\theta_{k, o n, u}$ (in rad) of the $u$ phase upper gate signal can be calculated as a function of the electrical frequency, the carrier frequency and the modulation index ${ }^{(6)}$. They are given by

$$
\begin{aligned}
& \theta_{k, \text { off }, u}=\frac{\theta_{c}}{4}\left(m_{a} \sin \left((k-1) \theta_{c}\right)-3+4 k\right) \cdots \cdots \cdots \\
& \theta_{k, \text { on }, u}=-\frac{\theta_{c}}{4}\left(m_{a} \sin \left(\left(k-\frac{1}{2}\right) \theta_{c}\right)+1-4 k\right) \ldots \ldots
\end{aligned}
$$

where $\theta_{c}$ is equal to $2 \pi F_{e} / F_{c}, k$ is an integer from 1 to $m_{c}$ and $m_{c}$ is equal to $F_{c} / F_{e}$. The switch OFF and switch ON points of the two other phases can be obtained by a simple $2 \pi / 3$ phase shift in (5) and (6).

By performing a Fourier transformation, it is possible to obtain the Fourier series of the $u$ phase upper gate signal. It 
follows

$$
C_{u}(\theta)=\frac{1}{2}+\sum_{n=1}^{\infty}\left(a_{n}\left(C_{u}\right) \cos (n \theta)+b_{n}\left(C_{u}\right) \sin (n \theta)\right)
$$

where $n$ is the harmonic order, $\theta$ is the electrical angle (between 0 and $2 \pi)$ and $a_{n}\left(C_{u}\right)$ and $b_{n}\left(C_{u}\right)$ are the Fourier coefficients of the signal. The coefficients depend on the switching times obtained in (5) and (6) and are given by

$$
\begin{aligned}
a_{n}\left(C_{u}\right)=\frac{1}{\pi n} \sum_{k=1}^{m_{c}}\left(\sin \left(n \theta_{k, o f f, u}\right)-\sin \left(n \theta_{k, o n, u}\right)\right) \\
\ldots \ldots \ldots \ldots \ldots \ldots \ldots \\
b_{n}\left(C_{u}\right)=-\frac{1}{\pi n} \sum_{k=1}^{m_{c}}\left(\cos \left(n \theta_{k, o f f, u}\right)-\cos \left(n \theta_{k, o n, u}\right)\right)
\end{aligned}
$$

The Fourier series of motor phase to neutral voltage can then be obtained from (8) and (9) using

$$
\left(\begin{array}{l}
V_{u n}(\theta) \\
V_{v n}(\theta) \\
V_{w n}(\theta)
\end{array}\right)=\left(\begin{array}{ccc}
\frac{2}{3} & -\frac{1}{3} & -\frac{1}{3} \\
-\frac{1}{3} & \frac{2}{3} & -\frac{1}{3} \\
-\frac{1}{3} & -\frac{1}{3} & \frac{2}{3}
\end{array}\right)\left(\begin{array}{l}
C_{u}(\theta) \\
C_{v}(\theta) \\
C_{w}(\theta)
\end{array}\right) \ldots \ldots \ldots \ldots
$$

The voltage harmonics amplitudes obtained using the developed model are presented in Fig. 7 and Fig. 8 for two values of $m_{a}$. The harmonics are compared with the FFT performed on the voltage waveforms obtained by measurement. It can be seen that the model gives results relatively close to the experimental data. Moreover, the fundamental remains the same for both modulation index values because the rotational speed is constant. Consequently, only the high order harmonics change. Knowing the harmonics amplitudes, calculating the voltage total harmonic distortion (THD) is quite straightforward. The THD values obtained from experimental measurements and model calculation are compared in Table 4.

\subsection{Calculation of Motor Phase Current Harmonics}

As explained in the previous section, the IPMSM rotates without load. Consequently, the fundamental of the phase current can be considered null as an approximation. This means that the fundamental of the phase voltage and the fundamental of the IPMSM back-EMF have no phase or amplitude difference. According to a preliminary measurement, the back-EMF of the $u$ phase can be approximated using the following equation.

$$
\begin{aligned}
e_{u}(\theta)= & 2 \pi F_{e}\left(\Psi_{f 1} \sin (\theta)+\Psi_{f 5} \sin \left(5 \theta+\phi_{f 5}\right)\right. \\
& \left.+\Psi_{f 7} \sin \left(7 \theta+\phi_{f 7}\right)\right) \ldots \ldots \ldots \ldots
\end{aligned}
$$

where $\Psi_{f 1}$ is equal to $0.0641 \mathrm{~V} . \mathrm{s} / \mathrm{rad}, \Psi_{f 5}$ is equal to $0.00232 \mathrm{~V} . \mathrm{s} / \mathrm{rad}, \Psi_{f 7}$ is equal to $0.00440 \mathrm{~V} . \mathrm{s} / \mathrm{rad}$, and $\varphi_{f 5}$ and $\varphi_{f 7}$ are almost equal to $-\pi$. Moreover, given the known relation between the inverter output voltage fundamental, $V_{d c}$ and $m_{a}$, it is possible to write

$$
2 \pi F_{e} \Psi_{f 1}=m_{a} \frac{V_{d c}}{2} \ldots
$$

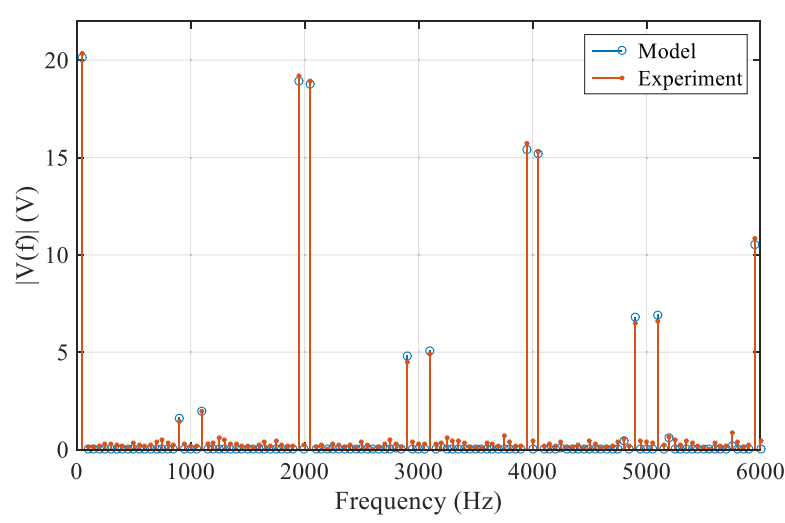

Fig. 7. Phase voltage harmonics amplitudes for $m_{a}=$ $0.230, F_{c}=1 \mathrm{kHz}$ and $F_{e}=50 \mathrm{~Hz}$

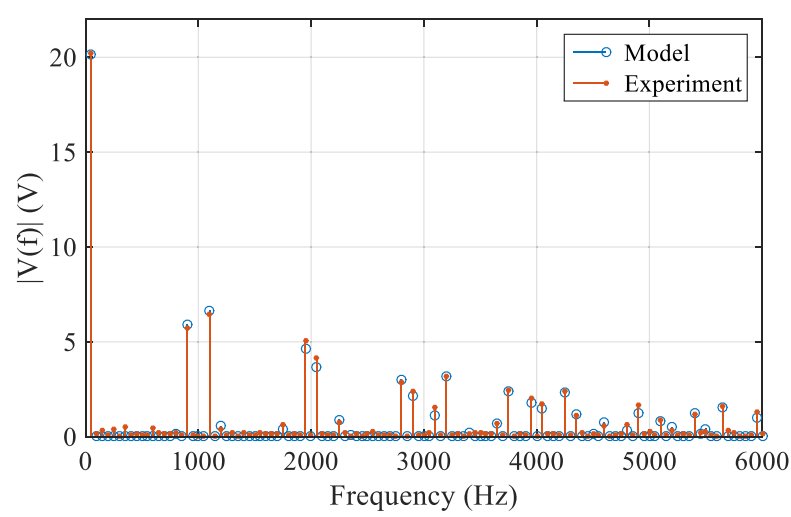

Fig. 8. Phase voltage harmonics amplitudes for $m_{a}=$ $0.975, F_{c}=1 \mathrm{kHz}$ and $F_{e}=50 \mathrm{~Hz}$

Table 4. Voltage THD comparison

\begin{tabular}{ccc}
\hline \hline & Model & Experiment \\
$m_{a}=0.230$ & $232 \%$ & $221 \%$ \\
$m_{a}=0.975$ & $71.5 \%$ & $72.5 \%$ \\
\hline \hline
\end{tabular}

In order to find an analytical expression of the phase current harmonics, it is proposed to perform a Clarke-Park transformation on the voltage expression found in (10) in order to obtain their expression in the rotating $(d, q)$ frame. By first performing the Clarke transformation, the phase voltage in the $(\alpha, \beta)$ frame is equal to

$$
\left(\begin{array}{l}
V_{\alpha}(\theta) \\
V_{\beta}(\theta)
\end{array}\right)=\sum_{n=1}^{\infty}\left(\begin{array}{l}
a_{n}\left(V_{\alpha}\right) \cos (n \theta)+b_{n}\left(V_{\alpha}\right) \sin (n \theta) \\
a_{n}\left(V_{\beta}\right) \cos (n \theta)+b_{n}\left(V_{\beta}\right) \sin (n \theta)
\end{array}\right)
$$

with

$$
\begin{aligned}
& a_{n}\left(V_{\alpha}\right)=\sqrt{\frac{2}{3}}\left(a_{n}\left(V_{u}\right)-\frac{1}{2} a_{n}\left(V_{v}\right)-\frac{1}{2} a_{n}\left(V_{w}\right)\right) \cdots \\
& b_{n}\left(V_{\alpha}\right)=\sqrt{\frac{2}{3}}\left(b_{n}\left(V_{u}\right)-\frac{1}{2} b_{n}\left(V_{v}\right)-\frac{1}{2} b_{n}\left(V_{w}\right)\right) \cdots \\
& a_{n}\left(V_{\beta}\right)=\frac{1}{\sqrt{2}}\left(a_{n}\left(V_{v}\right)-a_{n}\left(V_{w}\right)\right) \ldots \ldots \ldots \ldots \ldots \ldots \ldots \ldots \ldots \\
& b_{n}\left(V_{\beta}\right)=\frac{1}{\sqrt{2}}\left(b_{n}\left(V_{v}\right)-b_{n}\left(V_{w}\right)\right) \cdots \ldots \ldots \ldots
\end{aligned}
$$

where $a_{n}\left(V_{u}\right), a_{n}\left(V_{v}\right), a_{n}\left(V_{w}\right), b_{n}\left(V_{u}\right), b_{n}\left(V_{v}\right)$ and $b_{n}\left(V_{w}\right)$ are the Fourier series coefficients of the phase voltage in the $(u$, 
$v, w$ ) frame calculated using (10). Then by performing the Park transformation, the phase voltage in the $(d, q)$ frame is equal to

$$
\begin{aligned}
&\left(\begin{array}{l}
V_{d}(\theta) \\
V_{q}(\theta)
\end{array}\right)=\left(\begin{array}{l}
a_{0}\left(V_{d}\right) \\
a_{0}\left(V_{q}\right)
\end{array}\right) \\
&+\sum_{n=1}^{\infty}\left(\begin{array}{l}
a_{n}\left(V_{d}\right) \cos (n \theta)+b_{n}\left(V_{d}\right) \sin (n \theta) \\
a_{n}\left(V_{q}\right) \cos (n \theta)+b_{n}\left(V_{q}\right) \sin (n \theta)
\end{array}\right)
\end{aligned}
$$

with

$$
\begin{aligned}
& a_{0}\left(V_{d}\right)=\frac{1}{2}\left(a_{1}\left(V_{\alpha}\right)+b_{1}\left(V_{\beta}\right)\right) \\
& a_{0}\left(V_{q}\right)=\frac{1}{2}\left(a_{1}\left(V_{\beta}\right)-b_{1}\left(V_{\alpha}\right)\right) \\
& a_{n}\left(V_{d}\right)=\frac{1}{2}\left(a_{n+1}\left(V_{\alpha}\right)+b_{n+1}\left(V_{\beta}\right)+a_{n-1}\left(V_{\alpha}\right)-b_{n-1}\left(V_{\beta}\right)\right) \\
& b_{n}\left(V_{d}\right)=\frac{1}{2}\left(b_{n+1}\left(V_{\alpha}\right)-a_{n+1}\left(V_{\beta}\right)+b_{n-1}\left(V_{\alpha}\right)+a_{n-1}\right. \\
& a_{n}\left(V_{q}\right)=\frac{1}{2}\left(a_{n+1}\left(V_{\beta}\right)-b_{n+1}\left(V_{\alpha}\right)+b_{n-1}\left(V_{\alpha}\right)+a_{n-1}\left(V_{\beta}\right)\right) \\
& b_{n}\left(V_{q}\right)=\frac{1}{2}\left(b_{n+1}\left(V_{\beta}\right)+a_{n+1}\left(V_{\alpha}\right)+b_{n-1}\left(V_{\beta}\right)-a_{n-1}\left(V_{\alpha}\right)\right)
\end{aligned}
$$

It should be noted that when $n=1$ in (21) to (24), $a_{0}\left(V_{\alpha}\right)$, $b_{0}\left(V_{\alpha}\right), a_{0}(V \beta)$ and $b_{0}\left(V_{\beta}\right)$ are null.

After performing the same transformation on the backEMF, it is possible to write the phase current in the $(d, q)$ frame by using the IPMSM dynamic equation

$$
\begin{aligned}
\frac{d}{d t}\left(\begin{array}{c}
I_{d}(\theta) \\
I_{q}(\theta)
\end{array}\right)= & \left(\begin{array}{cc}
-\frac{R_{s}}{L_{d}} & \frac{2 \pi F_{e} L_{q}}{L_{d}} \\
-\frac{2 \pi F_{e} L_{d}}{L_{q}} & -\frac{R_{s}}{L_{q}}
\end{array}\right)\left(\begin{array}{l}
I_{d}(\theta) \\
I_{q}(\theta)
\end{array}\right) \\
& +\left(\begin{array}{cc}
\frac{1}{L_{d}} & 0 \\
0 & \frac{1}{L_{q}}
\end{array}\right)\left(\begin{array}{l}
V_{d}(\theta)-e_{d}(\theta) \\
V_{q}(\theta)-e_{q}(\theta)
\end{array}\right) .
\end{aligned}
$$

Since it is quite difficult to derive the expressions of the phase currents directly from (25), the following assumption is proposed. Since the fundamental of the phase currents have been taken null in the previous assumption, this means that the DC components of $I_{d}$ and $I_{q}$ are also null. Consequently, $I_{d}$ and $I_{q}$ only have high order harmonics due to the PWM and also a $6^{\text {th }}$ harmonic due to the back-EMF. It is then thought that (25) can be approximated to its expression at high frequency.

$$
\frac{d}{d t}\left(\begin{array}{c}
I_{d}(\theta) \\
I_{q}(\theta)
\end{array}\right)=\left(\begin{array}{cc}
\frac{1}{L_{d}} & 0 \\
0 & \frac{1}{L_{q}}
\end{array}\right)\left(\begin{array}{l}
V_{d}(\theta)-e_{d}(\theta) \\
V_{q}(\theta)-e_{q}(\theta)
\end{array}\right)
$$

In this way, the phase currents can be written

$$
\left(\begin{array}{l}
I_{d}(\theta) \\
I_{q}(\theta)
\end{array}\right)=\sum_{n=1}^{\infty}\left(\begin{array}{l}
a_{n}\left(I_{d}\right) \cos (n \theta)+b_{n}\left(I_{d}\right) \sin (n \theta) \\
a_{n}\left(I_{q}\right) \cos (n \theta)+b_{n}\left(I_{q}\right) \sin (n \theta)
\end{array}\right) \ldots
$$

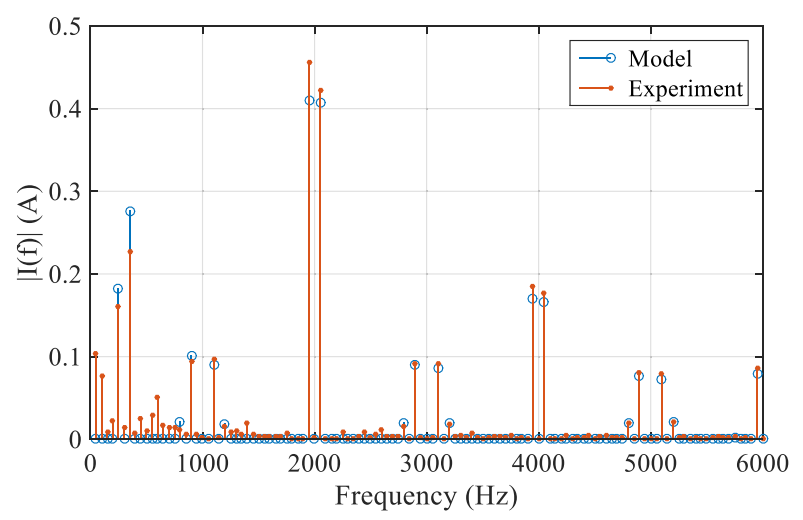

Fig. 9. Phase current harmonics amplitudes for $V_{d c}=$ $180 \mathrm{~V}, F_{c}=1 \mathrm{kHz}, F_{e}=50 \mathrm{~Hz}, m_{a}($ model $)=0.224$ and $m_{a}(\exp )=0.230$

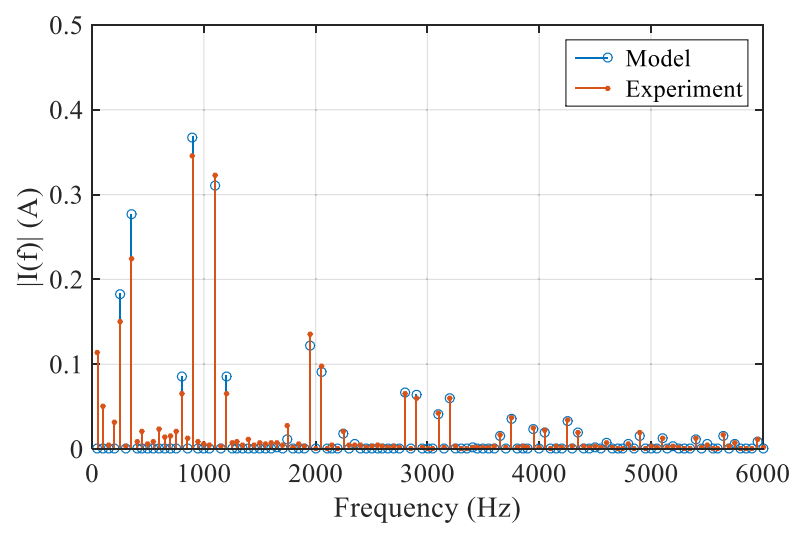

Fig. 10. Phase current harmonics amplitudes for $V_{d c}=$ $43 \mathrm{~V}, F_{c}=1 \mathrm{kHz}, F_{e}=50 \mathrm{~Hz}, m_{a}($ model $)=0.937$ and $m_{a}(\exp )=0.975$

with

$$
\begin{aligned}
& a_{n}\left(I_{d}\right)=\frac{1}{L_{d}}\left(-\frac{b_{n}\left(V_{d}\right)}{2 \pi n F_{e}}+\Psi_{d n}\right) . \\
& b_{n}\left(I_{d}\right)=\frac{a_{n}\left(V_{d}\right)}{L_{d} 2 \pi n F_{e}} \cdots \ldots \ldots \ldots \\
& a_{n}\left(I_{q}\right)=-\frac{b_{n}\left(V_{q}\right)}{L_{q} 2 \pi n F_{e}} \cdots \cdots \ldots . \\
& b_{n}\left(I_{q}\right)=\frac{1}{L_{q}}\left(-\frac{a_{n}\left(V_{q}\right)}{2 \pi n F_{e}}+\Psi_{q n}\right) .
\end{aligned}
$$

and

$$
\begin{aligned}
& \Psi_{d n}=\left\{\begin{array}{c}
-\sqrt{\frac{3}{2}}\left(\frac{\Psi_{f 5}+\Psi_{f 7}}{n}\right), \quad n=6 . \\
0, \quad n \neq 6
\end{array}\right. \\
& \Psi_{q n}=\left\{\begin{array}{cc}
\sqrt{\frac{3}{2}}\left(\frac{\Psi_{f 5}-\Psi_{f 7}}{n}\right), & n=6 \cdots \\
0, & n \neq 6
\end{array}\right.
\end{aligned}
$$

Equations (27) to (33) give an analytical form of the phase currents harmonics in the $(d, q)$ frame. Similarly to what was done from (13) to (24), the harmonics in the $(u, v, w)$ frame can be obtained by inverse Clarke-Park transformation. The obtained harmonic amplitudes are illustrated in Fig. 9 and Fig. 10 for $V_{d c}=180 \mathrm{~V}$ and $V_{d c}=43 \mathrm{~V}$ respectively. It can be seen that the fundamental component is neglected in the model due to the no-load approximation but, although low, 
it appears in the experimental data. This is due to the low electromagnetic torque that is actually needed to balance the iron losses and the mechanical friction losses. Moreover, the $5^{\text {th }}$ and $7^{\text {th }}$ harmonics of the current given by the model are higher than found by experiments. This is thought to be due to the approximation done in (26).

\section{Observation of Stator Magnetic Flux Density}

In the former sections, an expression of the high order harmonics caused by the PWM control on the IPMSM phase currents was established. Moreover the link between the PWM modulation index and the amplitude of these harmonics has been clarified. Those high order harmonics are responsible for magnetomotive forces originating from the stator windings and variating at high frequencies. These magnetomotive forces are responsible for high frequency variations of the magnetic flux density in the rotor, stator and magnets of the IPMSM. Ideally, the analysis should include an analytical calculation model of the magnetic flux density using a simplified linear magnetic model. However, this study is left for future work and in this section, measurements of the magnetic flux density in the stator is shown.

Besides the three-phase armature windings, additional coils are also wound on the stator core teeth and yoke parts in order to measure the average magnetic flux density. The coil has $N_{B}=10$ turns and delimits an open surface $S$ which is either the yoke or teeth surface. While the motor is rotating, the voltage $V_{b}$ induced in the coil is measured at a sampling frequency of $1 \mathrm{MHz}$. This voltage can be used to estimate the average magnetic flux density through the teeth or yoke surface using the equation

$$
B(t)=\frac{1}{N_{B} S} \int_{0}^{t} V_{b}(u) d u
$$

The measurements have been done at $V_{d c}$ equal to $43 \mathrm{~V}$ and $180 \mathrm{~V}$ and are illustrated in Fig. 11 and Fig. 12 for the teeth

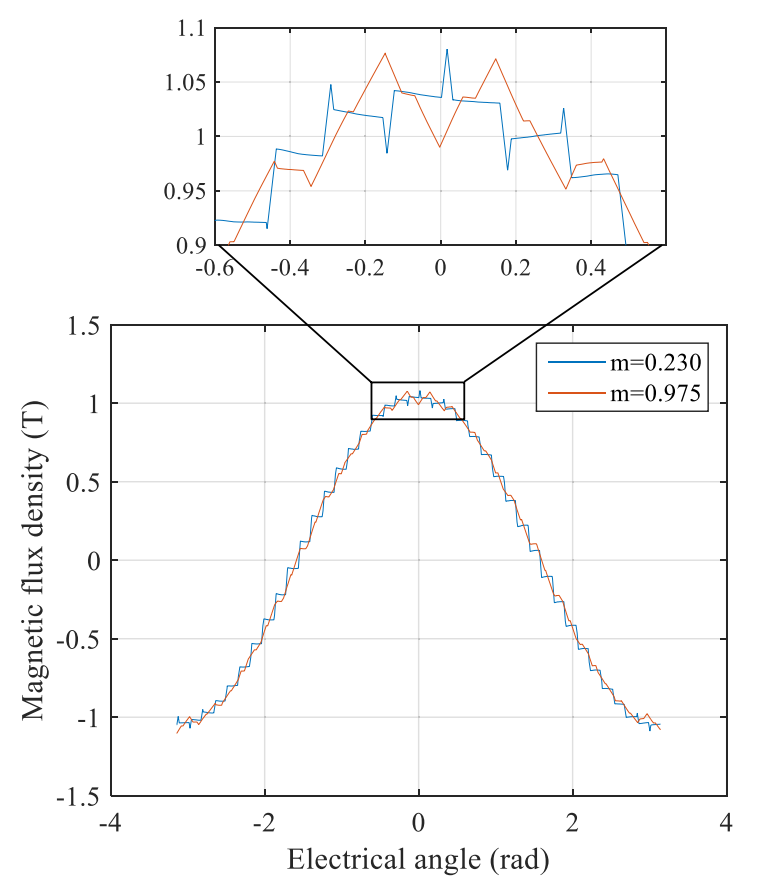

Fig. 11. Teeth magnetic flux density and yoke respectively. On the scale of the carrier frequency, the modulation index has a noticeable influence on the magnetic flux density waveform. Fig. 13 illustrates the FFT analysis on the teeth magnetic flux density. The fundamental stays unchanged because it is mainly due to the magnet rotation. Moreover, similarly to what is observed on the phase currents, the harmonics caused by the PWM control depend on the modulation index. At high modulation index, the strongest harmonics are around $1 \mathrm{kHz}$ while at low modulation index, the strongest harmonics occurs around $2 \mathrm{kHz}$ and $4 \mathrm{kHz}$. As in the voltage and current, the high order harmonics are stronger in case of low modulation index. In order to evaluate this phenomenon quantitatively, Table 6 shows the comparison between the low order harmonic contents and the high order harmonic contents. These contents are basically the rms value of the magnetic flux density harmonics in a given frequency range. It can be seen that at low modulation index, the high order harmonic content increases by

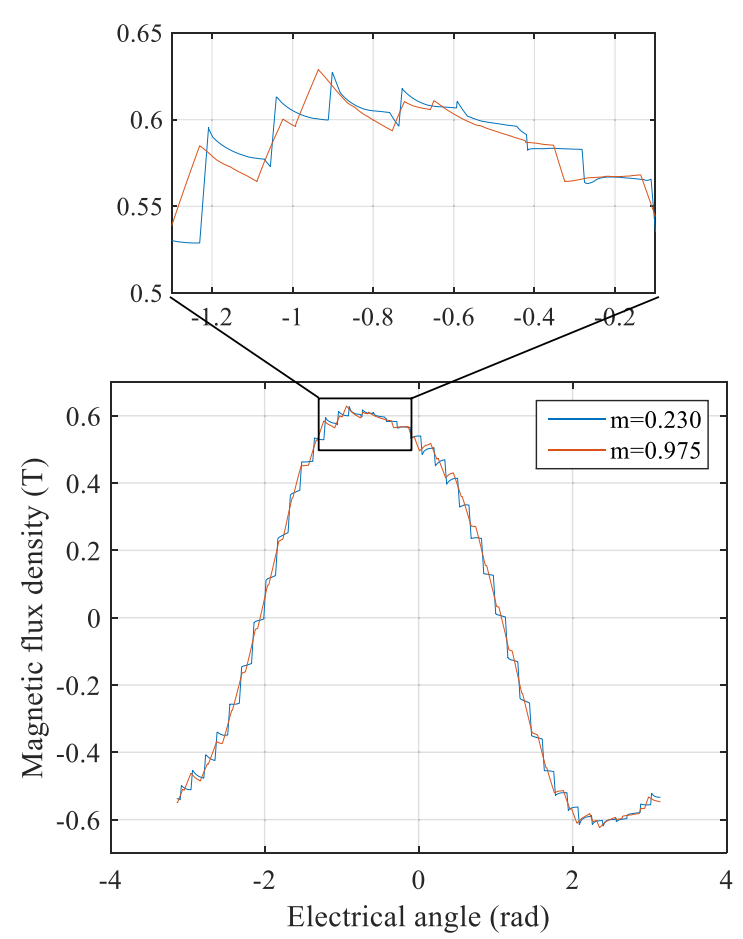

Fig. 12. Yoke magnetic flux density

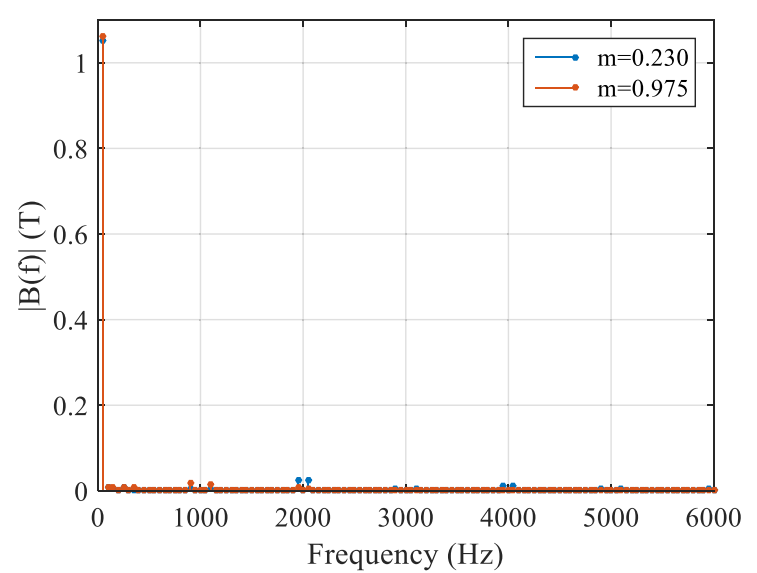

Fig. 13. FFT of the magnetic flux density measured on the teeth 
Table 5. Harmonic content comparison of teeth magnetic flux density

\begin{tabular}{ccc}
\hline \hline & $\begin{array}{c}\text { Low order harmonic } \\
\text { content }(100 \text { to } 1200 \\
\mathrm{Hz})\end{array}$ & $\begin{array}{c}\text { High order harmonic } \\
\text { content }(1.25 \text { to } 51.2 \\
\mathrm{kHz})\end{array}$ \\
\hline $\begin{array}{c}\mathrm{m}=0.230, \mathrm{Vdc} \\
=180 \mathrm{~V}\end{array}$ & $0.0108 \mathrm{~T}$ & $0.0410 \mathrm{~T}$ \\
$\mathrm{~m}=0.975, \mathrm{Vdc}$ & & \\
$=43 \mathrm{~V}$ & $0.0262 \mathrm{~T}$ & $0.0112 \mathrm{~T}$ \\
Increase rate & $-58.9 \%$ & $+267 \%$ \\
\hline \hline
\end{tabular}

more than $250 \%$ compared the high modulation index.

\section{Conclusion}

This paper proposes an experimental evaluation of the dependence between an IPMSM iron losses and the PWM modulation index used for inverter control. It is demonstrated that in no-load condition, the iron losses at a modulation index of 0.230 are 1.8 times higher than at a modulation index of 0.975. An analytical model that relates the PWM control parameters to the phase voltage and current harmonics has been developed and its validity was confirmed by comparison with experimental data. Using this model, the impact of the modulation index on the high order harmonics of the phase currents has been clarified. It is concluded that low modulation index increases the high order harmonic content of the phase current, which in turn increase the high order harmonic content of the magnetic flux density in the motor, then increasing the iron losses. In future works, an analytical linear magnetic model will be developed in order to relate the phase current harmonics to the high frequency magnetic flux density variations and then to the iron losses. Overall, the aim will be to relate the PWM modulation index to the iron losses of each part of the IPMSM.

\section{Acknowledgment}

This work was supported in part by the Ministry of Education, Culture, Sports, Science and Technology program, Japan, for private universities.

\section{References}

( 1 ) A. Boglietti, P. Ferraris, M. Lazzari, and F. Profumo: "Iron losses in magnetic materials with six-step and pwm inverter supply", IEEE Trans. Magn., Vol.27, No.6, pp.5334-5336 (1991)

( 2 ) K. Yamazaki and N. Fukushima: "Iron loss model for rotating machines using direct eddy current analysis in electrical steel sheets", IEEE Trans. Energy Convers., Vol.25, No.3, pp.633-641 (2010)

( 3 ) E. Dlala and A. Arkkio: "A general model for investigating the effects of the frequency converter on the magnetic iron losses of a squirrel-cage induction motor", IEEE Trans. Magn., Vol.45, No.9, pp.3303-3315 (2009)

(4) A. Boglietti, P. Ferraris, M. Lazzari, and F. Profumo: "Effects of different modulation index on the iron losses in soft magnetic materials supplied by PWM inverter", IEEE Trans. Magn., Vol.29, No.6, pp.3234-3236 (1993)

( 5 ) M. Kawabe, T. Nomiyama, A. Shiozaki, H. Kaihara, N. Takahashi, and M. Nakano: "Behavior of minor loop and iron loss under constant voltage type PWM inverter excitation", IEEE Trans. Magn., Vol.48, No.11, pp.3458-3461 (2012)
( 6 ) R. Liu, C.C. Mi, and D.W. Gao: "Modeling of eddy-current loss of electrical machines and transformers operated by pulsewidth-modulated inverters", IEEE Trans. Magn., Vol.44, No.8, pp.2021-2028 (2008)

( 7 ) K. Yamazaki and Y. Seto: "Iron loss analysis of interior permanent-magnet synchronous motors Variation of main loss factors due to driving condition", IEEE Trans. Ind. Appl., Vol.42, No.4, pp.1045-1052 (2006)

( 8 ) K. Yamazaki and A. Abe: "Loss investigation of interior permanent-magnet motors considering carrier harmonics and magnet eddy currents", IEEE Trans. Ind. Appl., Vol.45, No.2, pp.659-665 (2009)

( 9 ) P. Chen, R. Tang, W. Tong, X. Han, J. Jia, and X. Zhu: "Analysis of losses of permanent magnet synchronous motor with PWM supply", Proc. of 17th Int. Conf. on Electrical Machines and Systems (ICEMS 2014), Hangzhou, China, pp.1119-1124 (2014)

(10) E. Maruyama, S. Sumita, and A. Nakahara: "Evaluation of increasing rates in eddy-current loss of the motor due to carrier frequency", Proc. of Int. Conf. on Electrical Machines (ICEM 2014), Berlin, Germany, pp.1153-1157 (2014)

(11) N. Denis, K. Fujitani, Y. Kato, M. Ieki, and K. Fujisaki: "Core loss increase due to inverter carrier frequency in an interior permanent magnet synchronous motor", Proc. of $18^{\text {th }}$ Int. Conf. on Electrical Machines and Systems (ICEMS 2015), Pattaya, Thailand, pp.1-7 (2015)

Nicolas Denis (Non-member) was born in France in 1987. He re-

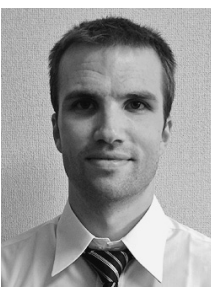
ceived the M.Eng. degree and the French Engineer Diploma degree in electrical engineering from the École Nationale Supérieure d'Électricité et de Mécanique de Nancy, Nancy, France, in 2010, and the Dr. Eng. degree in electrical engineering from Sherbrooke University, Sherbrooke, QC, Canada, in 2014. He was a Postdoctoral Fellow and Commissioned Scientist in the Toyota Technological Institute, Nagoya, Japan, from 2014 to 2017, in which he worked on electrical motors iron losses and application of efficient magnetic materials for electrical motors. He is currently engineer at Challenergy Inc., Tokyo, Japan.

Yenyi Wu (Non-member) was born in Taichung, Taiwan in 1992. She

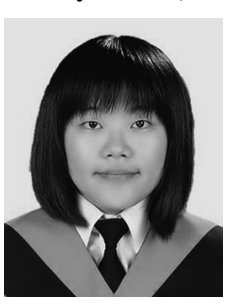
received the B.S. degree in electronic engineering from National Kaohsiung Normal University, Kaohsiung, Taiwan, in 2014. She is currently working toward the M.S. degree at National Chung Hsing University, Taiwan, and is now attending the double degree program between the Toyota Technological Institute, Japan, and National Chung Hsing University. Her research interests include Radio-Frequency integrated circuit design and the loss property of the iron core of the electrical motor.

Keisuke Fujisaki (Senior Member) received the B.Eng., M.Eng., and

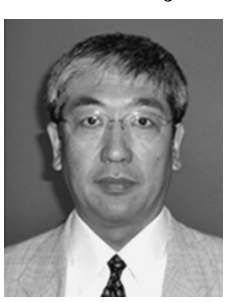
Dr. Eng. degrees in electronics engineering from the Faculty of Engineering, The University of Tokyo, Tokyo, Japan, in 1981, 1983, and 1986, respectively. From 1986 to 1991 , he conducted research on electromagnetic force applications to steel-making plants at the Ohita Works, Nippon Steel Corporation. From 1991 to 2010, he was a chief researcher in the Technical Development Bureau, Nippon Steel Corporation, Futtsu, Japan. Since 2010, he was a professor of Toyota Technological Institute. His current scientific interests are magnetic multi-scale, electromagnetic multi-physics, high efficient motor drive system, electrical motor, and power electronics. In 2002-2003, he was a Visiting Professor at Ohita University. In 2003-2009, he was a Visiting Professor at Tohoku University. Dr. Fujisaki received the Outstanding Prize Paper Award at the Metal Industry Committee sessions of the 2002 IEEE Industry Applications Society Annual Meeting. 